\title{
CFD Simulation of Combustion in Gas Turbine Engine
}

\author{
Xingxia $\mathrm{Hou}^{1, \text { a }}$, Shaolin Wang ${ }^{2, \mathrm{~b}}$, Pengfu Xie ${ }^{2, \mathrm{c}}$, Qing Gao ${ }^{2, \mathrm{~d}}$, \\ Chunqing $\operatorname{Tan}^{2, e}$ and Jianwen Wang ${ }^{1, f}$
}

\author{
${ }^{1}$ College of Energy and Power Engineering, Inner Mongolia University of Technology, Hohhot Inner \\ Mongolia 010051, China \\ ${ }^{2}$ Institute of Engineering Thermophysics, Chinese Academy of Sciences, Beijing 100190, China \\ a1060467092@qq.com, ${ }^{b}$ wangshaolin@iet.cn, cxiepengfu@iet.cn, dgaoqing@iet.cn, ${ }^{\mathrm{e}}$ tan@iet.cn, ${ }^{\mathrm{f}} \mathrm{w}$ \\ angjw@imut.edu.cn
}

Keywords: Numerical simulation, strong swirl combustor, turbulence model, combustion model.

\begin{abstract}
In order to investigate the liquid fuel combustion in gas turbine engine, the velocity of field and temperature of combustor in lean fuel injection model were numerically simulated and compared with the experimental data. The results show that the Realizable k- $\varepsilon$ turbulence model can simulate the combustion in the strong swirl combustion chamber well, and numerical results of the non-premixed combustion model and the DO heat transfer model were in good agreement with experimental data. According to the contrast of velocity field, it can be found that the recirculation zone expands in radial direction and contracts in axial direction for reacting case, which was compared with that of non-reacting case. This work laid the foundation for CFD simulation of gas turbine combustor and analysis of velocity profile.
\end{abstract}

\section{Introduction}

Combustion is a very complex physical and chemical reaction in combustor of the aircraft engine, and different from gaseous fuel diffusion combustion, because it contains the liquid fuel atomization. Liquid fuel combustion contains gas liquid two phase combustion. Fuel must atomize at first, evaporate, and mix with air. It is often close to evenly mixed gas combustion, and also has the diffusion combustion of the gas fuel, the diffusion combustion of the oil droplet and the combustion of oil droplet groups ${ }^{[1,2]}$. With the development of computer, the numerical simulation of gas flow, heat transfer and chemical reaction as an appreciate tool can effectively reduce the research cost and shorten the cycle, so that it becomes the main means of research ${ }^{[3,4]}$.

Numerous simulation has been made to investigate the liquid fuel combustion process. Saario ${ }^{[5]}$ simulated the flow in cylindrical combustor using different turbulence models. The results show that the RSM model is more suitable than the standard k- $\varepsilon$ turbulence mode for the simulation of high strong swirl-flow combustion chamber. Som ${ }^{[6]}$ studied liquid fuel combustion and injection characteristics of the gas turbine combustor with different pressures and swirl velocities. The results indicate that increasing vortex reduces the combustion efficiency under the condition of low pressure, while high pressure has reverse trend. Zhou ${ }^{[7]}$ studied the effect of swirl number on NO generation of turbulent combustion, The results show that with the increase of swirl number (from 0 to 1 ), the thermal NO emission rose firstly and then decreased, while the total NO and fuel NO emission showed a trend of decreased firstly and then increased. Guo ${ }^{[8]}$ used Euler model to simulate the droplet size distribution with reacting. The simulation results show that with the increase of droplet size, droplet heating rate decreased gradually, and the existence of the droplet area and survival time increased gradually. $\mathrm{Ma}^{[9]}$ simulated the flow and liquid combustion in a single venturi oil burner, and provided the velocity distribution, temperature profile which is useful for the design and operation of this type of fuel boiler. Oefelein ${ }^{[10,11]}$ used different turbulence models and combustion to simulate the spray and combustion processes. The present study is to simulate lean direct injection (LDI) combustion chamber, validate the turbulence model, combustion model and heat transfer model, and then analyzed the effect of droplet groups and the velocity profile in non-reacting flow and reacting flow. 


\section{Numerical Simulation}

\subsection{The Combustion Chamber Structure}

The combustion chamber geometry is based on a single head rectangular combustor used in Davoudzadeh's $^{[12]}$ experiments. The size of the chamber is $50.8 \mathrm{~mm} \times 50.8 \mathrm{~mm} \times 304.8 \mathrm{~mm}$, which consists of air inlet passage and rectangular combustion chamber. The air inlet passage is composed of an upstream air swirler and a converging-diverging venture section. There are six vanes with an inside diameter of $8.8 \mathrm{~mm}$ and an outside diameter of $22.5 \mathrm{~mm}$ (shown in figure 1). The installation angle of the swirl blade is 60 degree, and the swirl number is 1 .

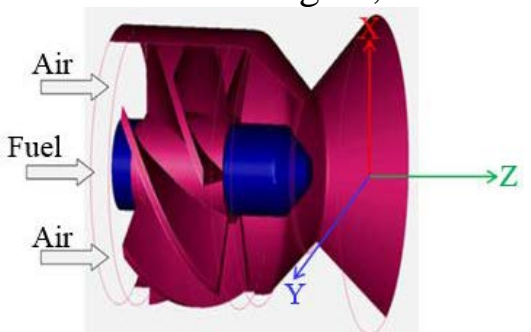

Fig. 1 Structure of the axial swirler

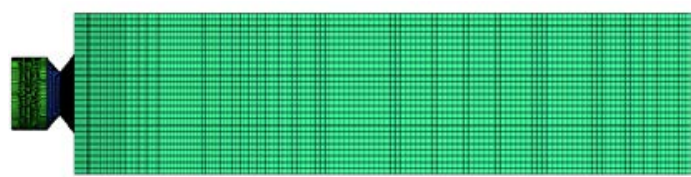

Fig. 2 Mesh of the combustor

\subsection{Mesh}

Ansys ICEM was used to mesh with hexahedral structured grid, and the total cells are about 520 thousand, as shown in figure 2.

\subsection{Boundary condition}

According to the experiments ${ }^{[13-14]}$, the inlet boundary is set as velocity inlet, and the speed is $20.14 \mathrm{~m} / \mathrm{s}$ with axial direction. The inlet temperature is $294.28 \mathrm{~K}$. The flow pressure is atmospheric pressure. The turbulent kinetic energy $(K)$ and the dissipation rate $(\varepsilon)$ are calculated as1.3383 and 2.015 .

The exit boundary condition is set to be the pressure outlet. The return flow turbulence intensity and hydraulic diameter are $10 \%$ and $50.8 \mathrm{~mm}$, respectively. The discrete phase boundary condition of inlet and outlet is set as escape. The wall is set to be smooth and without slip.

\section{Results and Discussion}

\subsection{Turbulence model}

Turbulence is important in computational fluid dynamics, and its salient features are random and non-constant, so it is difficult to predict the theory. It is necessary to put forward various assumptions on the transport process of turbulence, and link the various physical quantities in the turbulent transport process with the time-averaged flow field. Thus turbulence model is proposed.

In this study, realizable $k-\varepsilon$ turbulence mode which is suitable for strongly swirling flow is validated on the basis of numerical simulation of $\mathrm{Wu}[15]$. The computed components of the velocity along the x-coordinate is compared with the measured data for several axial stations, as shown in figure 3-5. Obviously, the numerical simulation results are in good agreement with the experimental data.

In Figure 3, it can been seen that at $5 \mathrm{~mm}$ downstream, the axial velocity profile shows an asymmetry image, which means the air inside the swirler doesn't mix well. The velocity distribution at this axial location is not uniform. As it is far away from the swirler, with the influence of its exit velocity, the velocity distribution decreases and becomes "U" type distribution.

Figure 4 shows that the radial velocity at the inlet of the combustion chamber is relatively large, and thus the large recirculation zone in the central area is generated. Then radial velocity decreases downstream the flow.

Figure 5 shows that at the exit of the near swirler, the swirling flow is strong, so the tangential velocity is large. Same as radial velocity, the tangential velocity decays downstream. 

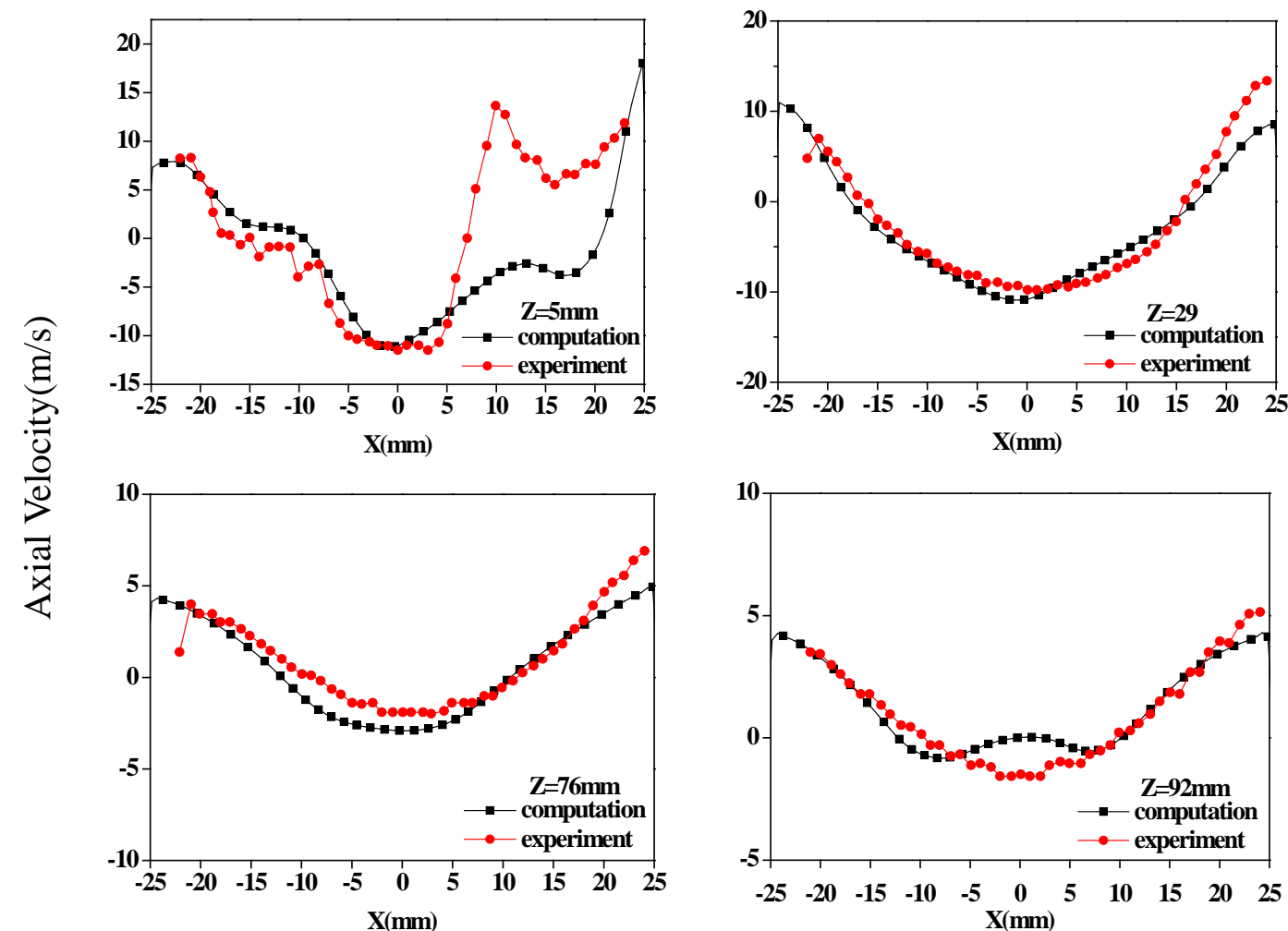

Fig. 3 Comparison of axial velocity with experimental data at different axial stations
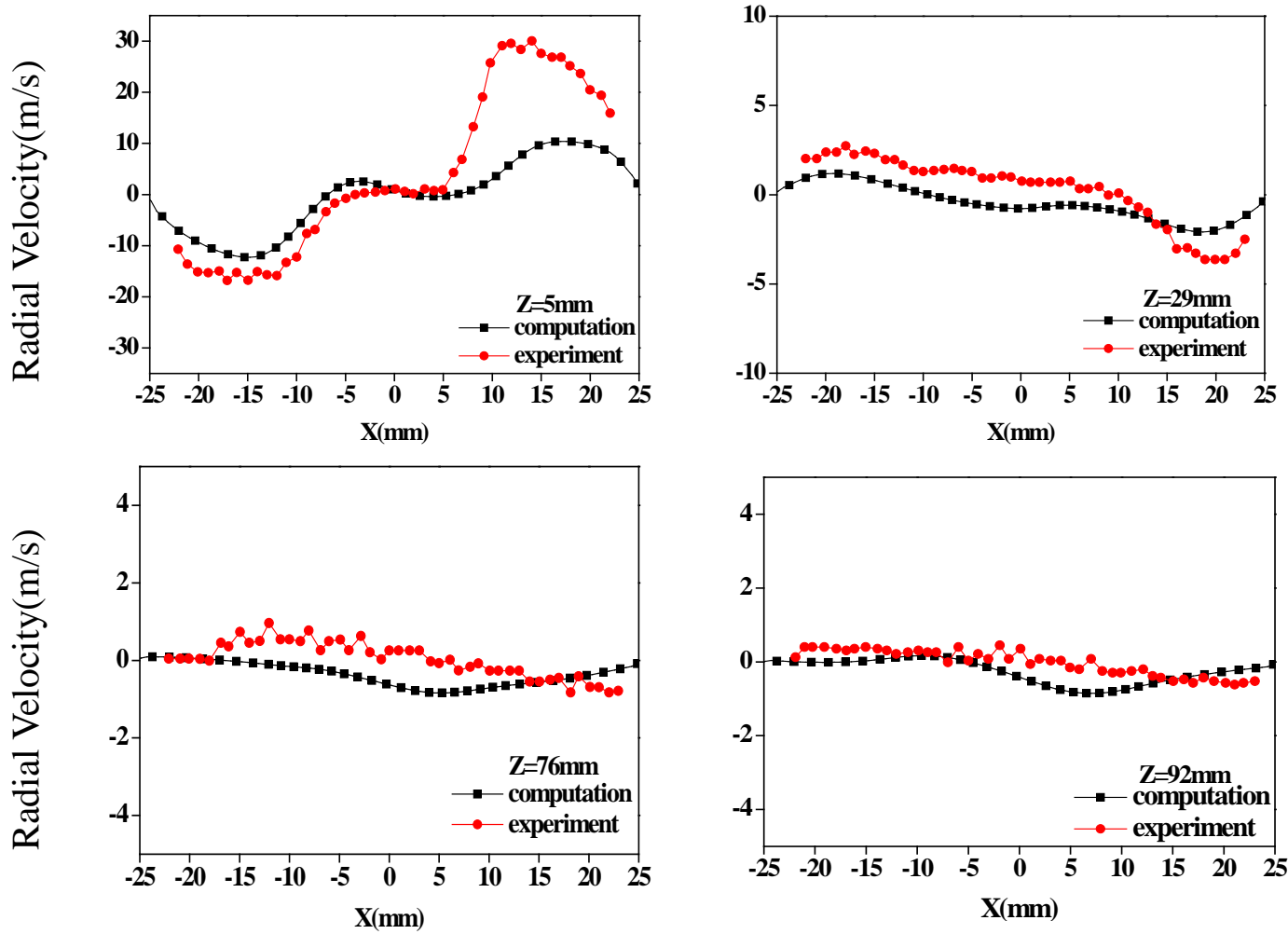

Fig. 4 Comparison of radial velocity with experimental data at different axial stations 

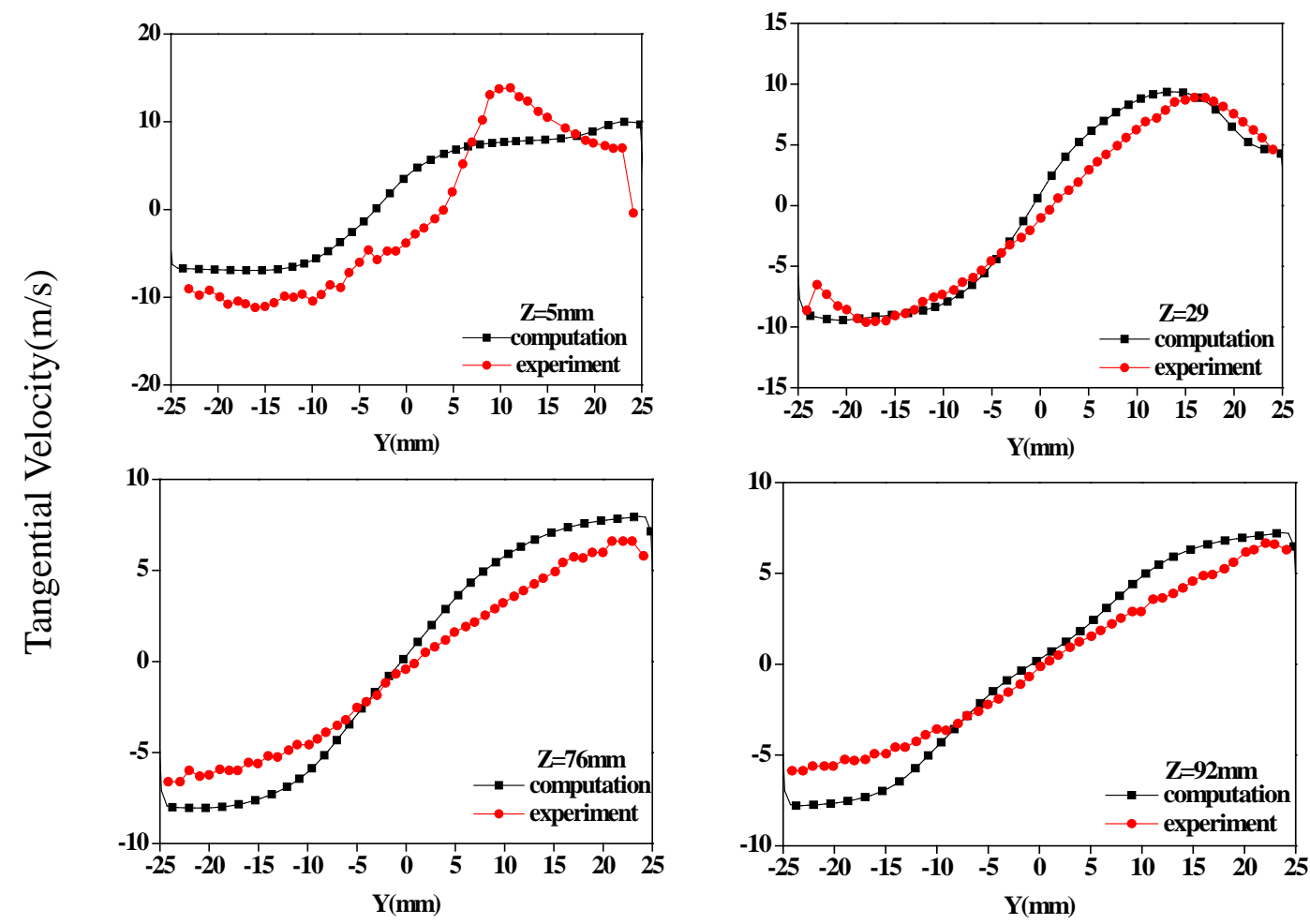

Fig. 5 Comparison of tangential velocity with experimental data at different axial stations

\subsection{Combustion and Radiation models}

The main reacting models include chemical transport model, non-premixed combustion model, premixed combustion model, partial premixed combustion model and so on. For present study, the flame is a typical turbulent diffusion flame. Thus we use non-premixed combustion model. DO radiation model which is applicable to combustion is used.

In Fluent, the liquid fuel $\mathrm{C}_{12} \mathrm{H}_{23}$ is adopted as kerosene used in experiments. The mass flow of the fuel is $0.415 \mathrm{~g} / \mathrm{s}$ with the inlet temperature $300 \mathrm{k}$. The spray cone angle is $90^{\circ}$. Figure 6 shows that comparison of temperature distribution with the experimental data along the center line. It can be seen from the figure that the calculated temperature distribution differs from the experimental data. The calculated temperature is higher than the experimental results. In fact, these deviations are caused by the thermocouple (when the temperature is greater than $1500 \mathrm{k}$ ) to produce a lot of heat loss and makes the measured temperature lower nearly $200 \mathrm{k}^{[16]}$.

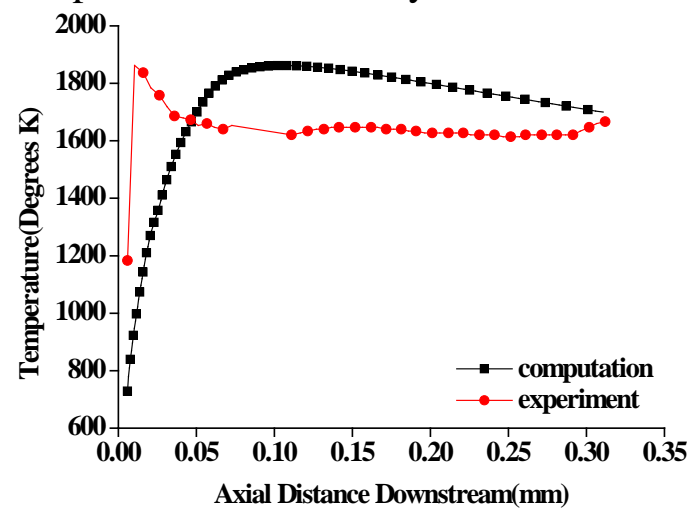

Fig. 6 Compared temperature distribution with the experimental data at the centerline

Obviously, it can be found that the calculated results are in good agreement with the experimental data. Therefore, non-premixed combustion model and DO radiation model is reasonable.

\subsection{Comparing velocity distribution of the non-reacting with reacting flow}

Figure 7 and 8 shows axial velocity contours of the non-reacting and reacting at central plane. From the figures, we can find that in the center of the combustion chamber region there is a recirculation zone which is conducive to the ignition and combustion stability. The recirculation zone of 
reacting state expands in the radial direction and shrinks in the axial direction comparing with non-reacting case. In order to clearly analyze the velocity distribution difference between non-reacting and reacting flow, the numerical simulation results of the non-reacting and reacting flow and experimental data were compared in figures 9-11.

Figure 9 shows comparison of reacting and Non-reacting axial velocity distributions. For instance, the axial velocities at $X=-10 \mathrm{~mm}$ and $X=5 \mathrm{~mm}$ are about $-4 \mathrm{~m} / \mathrm{s},-8 \mathrm{~m} / \mathrm{s}$, respectively, while in the reacting flow they are $18 \mathrm{~m} / \mathrm{s}, 13 \mathrm{~m} / \mathrm{s}$, respectively. It means that the heat release from the combustion intensifies the gas molecules thermal move, which causes the gas expansion and the significant gas velocity increase. The increase of axial velocity inhibit the recirculation zone length, and then the length of recirculation zone becomes shorter, as shown in figure 8.

Figure 10 shows non-reacting and reacting radial velocity distribution at different axial positions. Similar to axial velocity, the reacting gas has higher velocity values than non-reacting flow due to heat release and gas expansion. The increase of radial velocity make recirculation expand in the radial direction as shown in Figure 7 and 8 . At $Z=5 \mathrm{~mm}$, reacting and non-reacting velocity profiles show the expansion, but the peak velocity of reacting case is higher compared with the non-reacting case. At $\mathrm{Z}=29 \mathrm{~mm}$ downstream, radial velocity changes direction.

Figure 11 shows the tangential velocity distribution of the non-reacting and reacting cases at different axial positions. Both tangential velocities have the same trend, and the magnitude are nearly same. It indicates that the heat release has little effect on the tangential velocity.

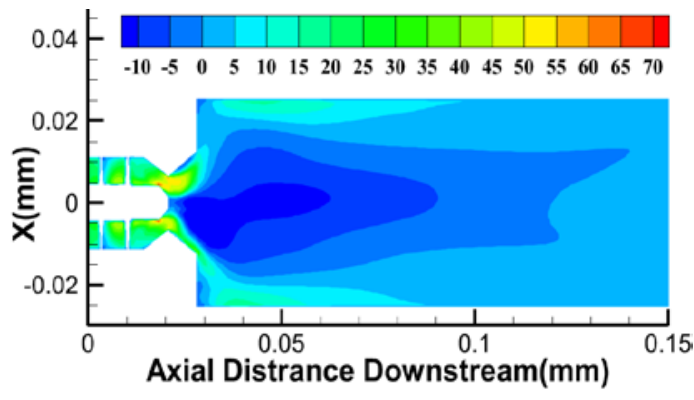

Fig. 7 Contours of axial velocity distributions central plane(non-reacting)

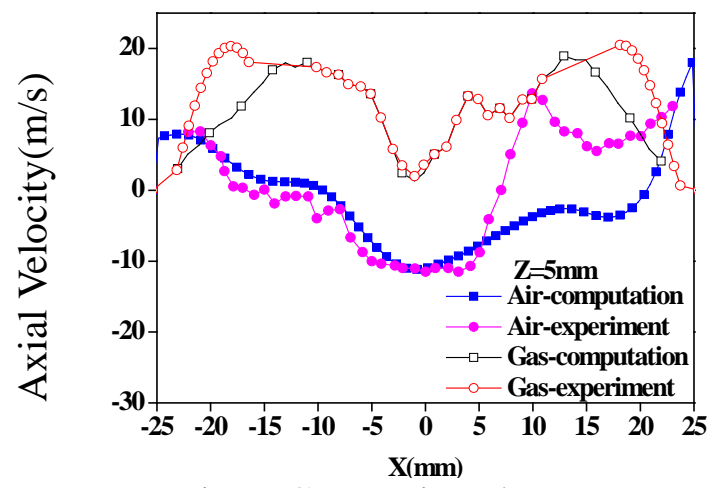

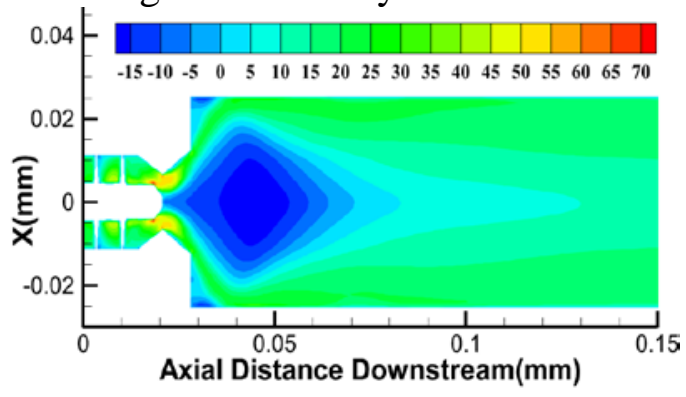

Fig. 8 Contours of axial velocity distribuations at central plane(reacting)

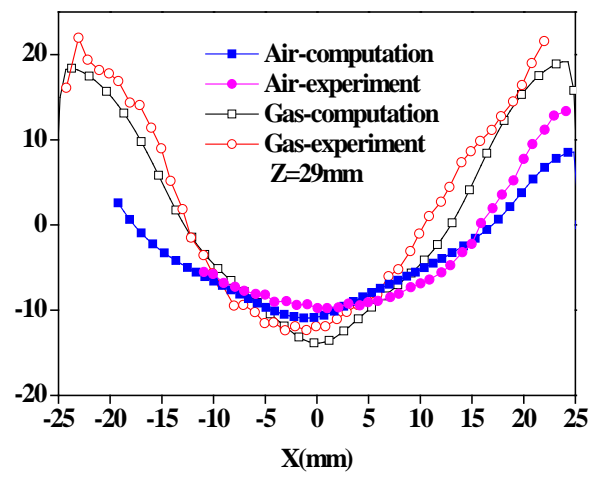

Fig. 9 Comparison between reacting and non-reacting axial velocity distributions
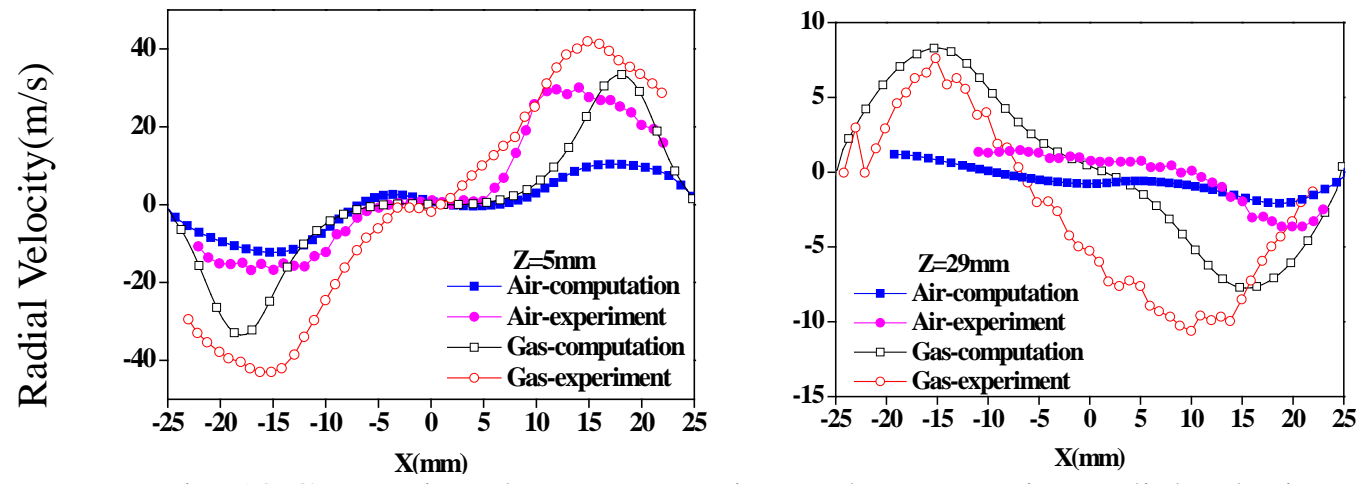

Fig. 10 Comparison between reacting and non-reacting radial velocity 


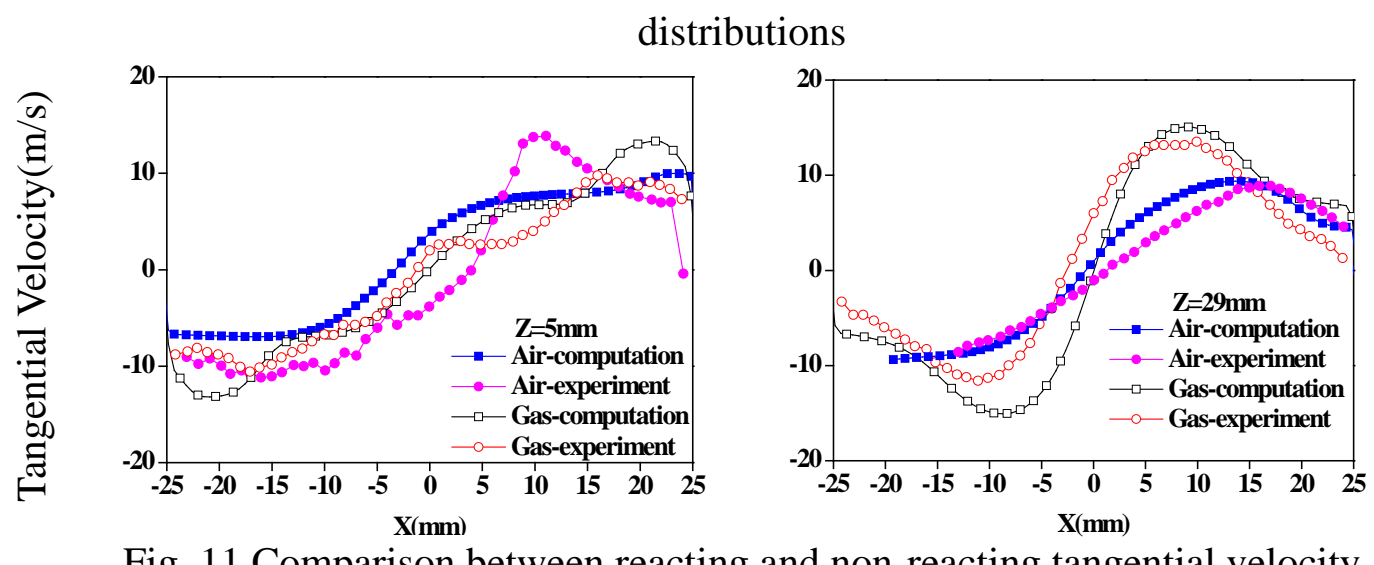

Fig. 11 Comparison between reacting and non-reacting tangential velocity distributions

\section{Conclusions}

Non-reacting and reacting flow in LDI combustion chamber were numerically simulated, the results show that:

Realizable k- $\varepsilon$ turbulence model, non-premixed combustion model and DO radiation model are suitable for numerical simulation of strong swirl combustion chamber, and the results of computation are in good agreement with the experimental data

Velocity of the calculation results and the experimental data indicates that axial and radial velocities in reacting case are higher than those of non-reacting case, while the tangential velocity has little difference for both case. Comparing with non-reacting case, the length of recirculation zone of reacting case is shorter.

\section{References}

[1] Z.Y. Peng, G. Liu, Y. Huang, Principle of Aviation Gas Turbine, National Defence of Industry Press, Beijing, 2008.

[2] R.S. Jin, Aviation gas turbine combustor, Aerospace press, Beijing, 1988.

[3] Y.M. Wang, W.Y. Qiao, L.J. Li, Application of Computer Simulation to the design of Aero Engine, Gas Turbine Experiment and Research, 18(2005)23-28.

[4] W.P. Jones, J.H. Whitelaw, Calculation methods for reacting turbulent flows: a review, Combustion and Flame, 48(1982)1-26.

[5] A. Saario, A. Rebola, P.J. Coelho, Heavy fuel oil combustion in a cylindrical laboratory furnace: measurements and modeling, Fuel, 84(2005)359-369.

[6] A. Datta, S.K. Som, Combustion and emission characteristics in a gas turbine combustor at different pressure and swirl conditions, Applied Thermal Engineering, 19(1999)949-967.

[7] L.X. Zhou., X.L. Chen, J. Zhang, Studies on the effect of swirl on no formation in turbulent combustion, Journal of Engineering Thermophysics, 23(2002)637-640.

[8] Y.C. Guo, W.Y. Lin, D. Wang, Pure Eulerian Model for Simulating Dilute Spray Combustion, Journal of Combustion Science and Technology, 6(2000)38-43.

[9] Z.S. Ma, S.P. Tu, S.G. Yao, Numerical Simulation of the Gas-liquid Two-phase Flow and Combustion in the Outlet of Venturi Burner, Journal of East China Shipbuilding Institute(Natural Sciences), 15(2001)77-81.

[10]J.C. Oefelein, V. Yang, Simulation of high-pressure spray field dynamics, Recent Advanced in Spar Combustion: Spray Combustion Measurements and Model Simulation, Journal of Fluids Engieering, 11(1996)263-300.

[11]A.A. Mostafa, H.C. Mongia, Computation of droplet dispersion in turbulent two-phase flows using the group splitting approach, International Journal of Heat and Mass Transfer, 30, (1987)2583-2593.

[12]F. Davoudzadeh, N.S. Liu, J.P. Moder, Investigation of Swirling Air Flows Generated by Axial 
Swirlers in a Flame Tube, American Society of Mechanical Engineers, (2006)891-902.

[13]J. Cai, S.M. Jeng, R. Tacina, The Structure of a Swirl-Stabilized Reacting Spray Issued from an Axial Swirler, AIAA 2005-1424, 43 ${ }^{\text {rd }}$ AIAA Aerospace Sciences Meeting and Exhibit, (2013).

[14]Y. Fu, S.M. Jeng, R. Tacina, Characteristics of the Swirling Flow Generated by an Axial Swirler, Proceedings of GT2005 ASME Turbo Expo 2005: Power for Land, Sea, and Air Jane (2005)6-9.

[15]C. Wu, Study on applicability of turbulent combustion model in the numerical calculation of combustor(2009).

[16]S.S. Xu, Z.M. Shi, G. Yang, Error model and application of temperature measure about thermocouple based on heat transfer principle, Transducer and Microsystem Technologies, 25(2006)15-18. 